\title{
Chemical Technology
}

DOI: http://doi.org/10.20914/2310-1202-2019-4-178-183

УДК 678.742.2

Оригинальная статья/Research article

\section{Влияние состава композиционного активатора вулканизации}

\section{на свойства эластомеров}

$\begin{array}{llll}\text { Ольга В. Карманова } & 1 & \text { karolga@mail.ru } & \text { (D) 0000-0003-2226-6582 } \\ \text { Анастасия Ю. Фатнева } & 1 & \text { doroxinanastja@mail.ru } & \text { (D) 0000-0003-0109-7222 } \\ \text { Сергей Г. Тихомиров } & 1 & \text { tikhomirov_57@mail.ru } & \text { (D) 0000-0002-8192-0049 } \\ \text { Любовь В. Попова } & 1 & \text { luba030883@yandex.ru } & \text { (D) 0000-0002-9648-7620 }\end{array}$

1 Воронежский государственный университет инженерных технологий, пр-т Революции, 19, г. Воронеж, 394036, Россия

Аннотация. Исследованы свойства резиновых смесей и вулканизатов, изготовленных с применением композиционного активатора вулканизации (КАВ) с пониженным содержанием оксида цинка. Разработаны технологические режимы получения новых активаторов вулканизации в виде сплава оксида цинка со смесью жирных кислот. Для придания удобной выпускной формы в состав опытных продуктов вводили тонкодисперсные наполнители разных типов: диоксид кремния, технический углерод, микроцеллюлозу, бентонит, шунгит. Изучены физико-химические свойства КАВ и установлено, что по значениям кислотного, иодного чисел опытные продукты удовлетворяют нормативным требованиям, предъявляемым к стеариновой кислоте. Проведен сопоставительный анализ свойств эластомеров опытных продуктов с широко применяемыми в качестве активаторов вулканизации оксидом цинка и стеариновой кислотой. Установлено, что использование опытных продуктов улучшает перерабатываемость композиций благодаря лучшему их диспергированию в эластомерной среде. Определены соотношения компонентов КАВ, обеспечивающие оптимальный комплекс вулканизационных и физико-механических свойств эластомеров, изготовленных на их основе. Показана эффективность действия КАВ при изготовлении эластомерных изделий - отмечено сокращение цикла смешения опытных композиций в среднем на 10 \% по сравнению со стандартной резиновой смесью. Анализ результатов исследования подтвердил улучшение технологических и вулканизационных свойств резиновых смесей, стойкости к скорчингу. Показано, что применение композиционных активаторов вулканизации обеспечивает требуемый уровень физико-механических свойств резин даже при снижении содержания в опытном продукте оксида цинка до 20 \% мас., а также улучшает диспергирование компонентов резиновой смеси, оказывая положительное влияние на технологические и вулканизационные свойства резиновых смесей.

Ключевые слова: резиновые смеси, смесь жирных кислот, оксид цинка, активатор вулканизации

\section{The effect of the compositional curing activator formation on the properties of elastomers}

\begin{tabular}{llll}
\hline \hline Olga V. Karmanova & 1 & karolga@mail.ru & (D) 0000-0003-2226-6582 \\
Anastasia Yu. Fatneva $^{1}$ & doroxinanastja@mail.ru & (D) 0000-0003-0109-7222 \\
Sergei G. Tikhomirov & 1 & tikhomirov_57@ mail.ru & (D) 0000-0002-8192-0049 \\
Lubov V. Popova & 1 & luba030883@yandex.ru & (D) 0000-0002-9648-7620 \\
\hline
\end{tabular}

1 Voronezh State University of Engineering Technologies, Revolution Av., 19 Voronezh, 394036, Russia

Abstract. The properties of rubber compounds and vulcanizates made using a compositional curing activator with a low content of zinc oxide were studied in this work. Technological modes of obtaining new curing activator activators in the form of an alloy of zinc oxide with a mixture of fatty acids have been developed. To give a convenient outlet shape, finely dispersed fillers of various types were introduced into the experimental products: silicon dioxide, carbon black, microcellulose, bentonite, shungite. The physicochemical properties of compositional curing activator were studied and it was established that, according to the values of acid and iodine numbers, the experimental products satisfy the regulatory requirements for stearic acid. A comparative analysis of the properties of elastomers of experimental products with widely used as curing activator activators of zinc oxide and stearic acid is carried out. It was found that the use of experimental products improves the processability of the compositions due to their better dispersion in an elastomeric medium. The ratios of the compositional curing activator components are determined, which ensure the optimal complex of vulcanization and physical and mechanical properties of elastomers made on their basis. The effectiveness of the action of composite vulcanization activator in the manufacture of elastomeric products is shown - a reduction in the mixing cycle of experimental compositions by an average of $10 \%$ is noted compared to the standard rubber compound. The analysis of the research results confirmed the improvement of technological and vulcanization properties of rubber compounds, resistance to scorching. It is shown that the use of compositional curing activators provides the required level of physical and mechanical properties of rubbers even with a decrease in the content of zinc oxide in the experimental product to $20 \mathrm{wt} \%$, and also improves the dispersion of the components of the rubber compound, having a positive effect on the technological and vulcanization properties of rubber compounds. Keywords: rubber compounds, a mixture of fatty acids, zinc oxide, curing activator

Для цитирования

Карманова О.В., Фатнева А.Ю., Тихомиров С.Г., Попова Л.В. Влияние состава композиционного активатора вулканизации на свойства эластомеров // Вестник ВГУИТ. 2019. Т. 81. № 4. С. 178-183. doi:10.20914/2310-1202-2019-4-178-183

(C)2019, Карманова O.В. и др. / Karmanova O.V. et al
For citation

Karmanova O.V., Fatneva A.Yu., Tikhomirov S.G., Popova L.V The effect of the compositional curing activator formation on the properties of elastomers. Vestnik VGUIT [Proceedings of VSUET]. 2019. vol. 81. no. 4. pp. 178-183. (in Russian). doi:10.20914/2310-1202-2019-4-178-183

This is an open access article distributed under the terms of the Creative Commons Attribution 4.0 International License 


\section{Введение}

Вулканизация является одним из важнейших процессов в технологии производства резиновых изделий. Как заключительный процесс получения резиновых изделий с заданными свойствами вулканизация имеет как теоретическое, так и практическое значение. Сложность протекающих при этом химических процессов, их специфичность для каучуков различной природы и строения обусловили исследования в этой области. К настоящему времени накоплен обширный экспериментальный материал по применению соединений различных классов в качестве вулканизующих агентов и механизму их действия, выявлен ряд общих закономерностей, связывающих особенности вулканизационных структур с физико-механическими свойствами резин и разработаны технологические процессы получения резиновых изделий на основе каучуков различных типов [1-3]. При создании эластомерных материалов необходимо учитывать взаимодействие между компонентами вулканизующих групп, на что указывает возрастающее количество исследований по данному направлению: создание синергических смесей ускорителей и активаторов вулканизации, молекулярных комплексов, эвтектических смесей для структурирования эластомеров и др. [4-7].

В настоящее время отечественная промышленность располагает ограниченным ассортиментом компонентов вулканизующих групп, в связи с чем создание новых ингредиентов, в частности активаторов вулканизации, для удовлетворения потребностей резиновой промышленности представляется весьма актуальной задачей. Кроме того, на современном этапе производства вследствие высоких требований к готовым изделиям отмечаются определенные тенденции, связанные с повышением экологических требований к производимой продукции [8-10]. Таким образом, создание активирующих систем из комбинаций многоцелевых ингредиентов полифункционального действия, которые позволят оптимизировать технологию получения эластомеров, является важнейшей резинотехнической задачей в области химической технологии резины [11].

Цель работы - изучение свойств эластомеров, содержащих композиционные активаторы вулканизации с пониженным содержанием оксида цинка.

\section{Материалы и методы}

Объектами исследования являлись композиционные активаторы вулканизации (КАВ), которые получали в виде сплавов оксида цинка (ГОСТ 202-84) с жирными кислотами (технический продукт ОАО «Евдакоский МЖК»). В состав активаторов были включены тонкодисперсные наполнители разной природы для обеспечения удобной выпускной формы в виде непылящего порошка: шунгитовый порошок марки «Новокарбон» (ТУ 2169-00157753937-2002), диоксид кремния марки Б -120 (ГОСТ 18307-78), гранулированный технический углерод П-803 (ТУ 2166-002-66399044-2011), бентонит марки «TONSIL» (ТУ 5751-00178035873-05), кристаллическая микроцеллюлоза (ТУ 9199-001-07508109).

Активаторы вулканизации получали в реакторе при $80{ }^{\circ} \mathrm{C}$ в течение 10 мин. Для изучения технологических, вулканизационных свойств резиновых смесей и физико-механических показателей вулканизатов с использованием КАВ изготавливали резиновые смеси на основе каучука СКС-30АРК по стандартной рецептуре бутадиен-стирольного каучука в соответствии с ASTMD 3185.

Композиции по стандартной рецептуре бутадиен-стирольного каучука готовили на лабораторных вальцах с фрикцией 1,00:1,28 и температурой поверхности валков $(50 \pm 5){ }^{\circ} \mathrm{C}$. Время смешения составляло 20 мин. Образцы для физико-механических испытаний получали прессованием композиций в вулканизационном прессе под давлением 50 МПа при $145^{\circ} \mathrm{C}$ в течение 35 мин.

Использовали стандартные методы исследования, широко применяемые для изучения структуры и свойств полимеров: определение вязкости по Муни (ГОСТ Р 54552-2011), вулканизационных характеристик - на реометре (ГОСТ 12535-84), твердости - по Шору А (ГОСТ 263-75), упруго-прочностных свойств при растяжении (ГОСТ 270-75), испытание на стойкость в ненапряженном состоянии к воздействию жидких агрессивных сред (ГОСТ 9.030 - 74).

\section{Результаты и обсуждение}

Для определения оптимального соотношения составляющих КАВ и влияния на основные свойства резиновых смесей и вулканизатов (время достижения оптимума вулканизации $\tau_{90}$, условное напряжение при удлинении на 300 \%) использовали метод планирования эксперимента ПФЭ $2^{3}$. В итоге было выбрано соотношение СЖК:ZnO:Наполнитель=43:26:31 [11].

Свойства полученных КАВ контролировали по показателям: температура застывания, массовая доля влаги, кислотное и йодное число (таблица 1). 
Таблица 1 .

Свойства активаторов вулканизации

Table 1.

Properties of vulcanization activators

\begin{tabular}{|c|c|c|c|c|c|c|}
\hline $\begin{array}{l}\text { Показатель } \\
\text { Indicator }\end{array}$ & $\begin{array}{c}\text { Стеариновая } \\
\text { кислота Т-32 } \\
\text { Stearic acid T } 32\end{array}$ & $\begin{array}{l}\text { KAB-Ш } \\
\text { CVA-S }\end{array}$ & $\begin{array}{l}\text { KAB-БC } \\
\text { CVA-SW }\end{array}$ & $\begin{array}{l}\text { KAB-TУ } \\
\text { CVA-TC }\end{array}$ & $\begin{array}{l}\text { KAB-Б } \\
\text { CVA-B }\end{array}$ & $\begin{array}{l}\text { КАВ-МКЦ } \\
\text { CVA-MCC }\end{array}$ \\
\hline $\begin{array}{l}\mathrm{T}_{\text {застыв }},{ }^{\circ} \mathrm{C} \text {, не ниже } \\
\mathrm{T}_{\text {Weave, }},{ }^{\circ} \mathrm{C} \text {, not less than }\end{array}$ & 50 & 49 & 49 & 49 & 49 & 49 \\
\hline $\begin{array}{l}\text { Массовая доля влаги, \%, не более } \\
\text { Mass fraction of moisture, } \%, \text { max. }\end{array}$ & 0,2 & 0,3 & 0,2 & 0,2 & 0,5 & 0,5 \\
\hline $\begin{array}{l}\text { Кислотное число, мг КОН/г } \\
\text { Acid number, mg KOH/g }\end{array}$ & 205 & 198 & 198 & 198 & 198 & 198 \\
\hline $\begin{array}{l}\text { Йодное число, } г I_{2} / \Gamma \text {, не более } \\
\text { Iodine number, } \mathrm{I}_{2} / \mathrm{g}, \max \end{array}$ & 20 & 30 & 30 & 30 & 30 & 30 \\
\hline
\end{tabular}

Анализ данных табл. 1 показал, что опытные продукты по значениям кислотного и йодного чисел удовлетворяют нормативным требованиям на стеариновую кислоту (ГОСТ 6484-96).

КАВ были испытаны в стандартной резиновой смеси на основе каучука СКС-30 АРК. В рецептуре стандартных смесей оксид цинка (3 мас. ч.) и стеариновую кислоту (1 мас. ч.) заменяли опытным продуктом (4 мас. ч.). При изготовлении композиций отмечено улучшение их обрабатываемости с использованием опытных активаторов вулканизации при сокращении времени цикла смешения в среднем на $10 \%$.

Результаты исследований технологических свойств и вулканизационных характеристики резиновых смесей с опытными активаторами вулканизации представлены в таблица 2.

Анализ технологических и вулканизационных свойств резиновых смесей показал, что тип наполнителя в целом мало влияет на значения вязкости по Муни, применение бентонита в составе КАВ (образец КАВ-Б) привело к уменьшению вязкости до 62 усл. ед., а техуглерода

(образец КАВ-ТУ) - к повышению вязкости резиновых смесей до 70 усл. ед.

Отмечено, что данные вязкости по Муни не согласуются с значениями минимального крутящего момента $\mathrm{M}_{\min }$ при обработке на реометре Монсанто, который несколько ниже у опытных образцов (как и максимальный крутящий момент $\mathrm{M}_{\max }$, и момент достижения степени вулканизации $90 \%-\mathrm{M}_{90}$ ). Это, очевидно, связано с тем, что при повышенной температуре $\left(160{ }^{\circ} \mathrm{C}\right.$ на реометре против $100{ }^{\circ} \mathrm{C}$ на вискозиметре Муни) смесь жирных кислот и цинковые мыла, образующиеся в процессе вулканизации, обеспечивают лучшие реологические характеристики резиновых смесей. Время начала вулканизации $\tau_{\mathrm{s}}$ исследуемых образцов колеблется в пределах от 1,5 мин у образцов с МКЦ (КАВМКЦ) до $\approx 4$ мин у образцов с шунгитом (КАВ-Ш). Следует отметить, что время начала вулканизации опытных образцов меньше, чем у стандартного. Время достижения оптимума вулканизации $\tau_{90}$ у всех исследуемых образцов значительно меньше стандартного в 1,5-2 раза.

Таблица 2 .

Технологические свойства и вулканизационные характеристики резиновых смесей с опытными активаторами вулканизации

Table 2 .

Technological properties and vulcanization characteristics of rubber compounds with experienced curing activators

\begin{tabular}{|c|c|c|c|c|c|c|}
\hline \multirow[b]{2}{*}{ Показатель | Indicator } & \multicolumn{6}{|c|}{\begin{tabular}{l|l|l} 
Шифры образцов & Codes of samples \\
\end{tabular}} \\
\hline & $\begin{array}{l}\text { Стандартный } \\
\text { Standard }\end{array}$ & $\begin{array}{l}\text { KAB-Ш } \\
\text { CVA-S }\end{array}$ & $\begin{array}{l}\text { KAB-БC } \\
\text { CVA-SW }\end{array}$ & $\begin{array}{l}\text { KAB-TУ } \\
\text { CVA-TC } \\
\end{array}$ & $\begin{array}{l}\text { KAB-Б } \\
\text { CVA-B } \\
\end{array}$ & $\begin{array}{l}\text { КАВ-МКЦ } \\
\text { CVA-MCC }\end{array}$ \\
\hline $\begin{array}{l}\text { Вязкость по Муни ML }(1+4) 100^{\circ} \mathrm{C} \text {, усл. ед. } \\
\text { Mooney viscosity ML }(14) 100^{\circ} \mathrm{C} \text {, unit. }\end{array}$ & 68 & 68 & 69 & 70 & 62 & 68 \\
\hline \multicolumn{7}{|c|}{$\begin{array}{l}\text { Реометрия, } 160^{\circ} \mathrm{C}, 30 \text { мин } \mid \text { Rheometry, } 160^{\circ} \mathrm{C}, 30 \mathrm{~min}\end{array}$} \\
\hline 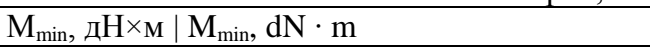 & 10,0 & 10,0 & 9,0 & 8,9 & 9,5 & 8,7 \\
\hline \begin{tabular}{l|l}
$\mathrm{M}_{\max }, д \mathrm{H} \times \mathrm{M}$ & $\mathrm{M}_{\max }, \mathrm{dN} \cdot \mathrm{m}$ \\
\end{tabular} & 40,8 & 37,5 & 36,5 & 36,2 & 37,0 & 35,5 \\
\hline \begin{tabular}{l|l}
$\mathrm{M}_{90}, \mathrm{дH} \times \mathrm{M}$ & $\mathrm{M}_{90}, \mathrm{dN} \cdot \mathrm{m}$ \\
\end{tabular} & 37,7 & 34,7 & 33,7 & 33,5 & 34,2 & 32,8 \\
\hline \begin{tabular}{l|l}
$\tau_{\mathrm{s}}$, мин & $\tau_{\mathrm{s},}$ minutes \\
\end{tabular} & 3,2 & 3,8 & 2,0 & 1,7 & 2,3 & 1,5 \\
\hline \begin{tabular}{l|l}
$\tau_{90}$, мин & $\tau_{90,}$, minutes \\
\end{tabular} & 21,1 & 15,8 & 16,2 & 14,8 & 16,2 & 15,2 \\
\hline \begin{tabular}{l|l}
$\Delta \tau$, мин $^{-1}$ & $\Delta \tau$, minutes $^{-1}$ \\
\end{tabular} & 5,5 & 8,3 & 7,0 & 7,6 & 7,2 & 7,3 \\
\hline
\end{tabular}


Общая скорость вулканизации $\Delta \tau$ у всех опытных образцов значительно выше, чем у образца без наполнителей. Высокую скорость вулканизации показали образцы с шунгитом (КАВ-Ш), белой сажей (КАВ-БС).

Анализ физико-механических показателей показал (рисунок 1), что резины имели высокие модули при растяжении на $300 \%-\mathrm{M}_{300}$ (образцы с шунгитом, техуглеродом, МКЦ). Это указывает на образование эффективной пространственной сетки вулканизтов, полученных в присутствии данных активаторов вулканизации.

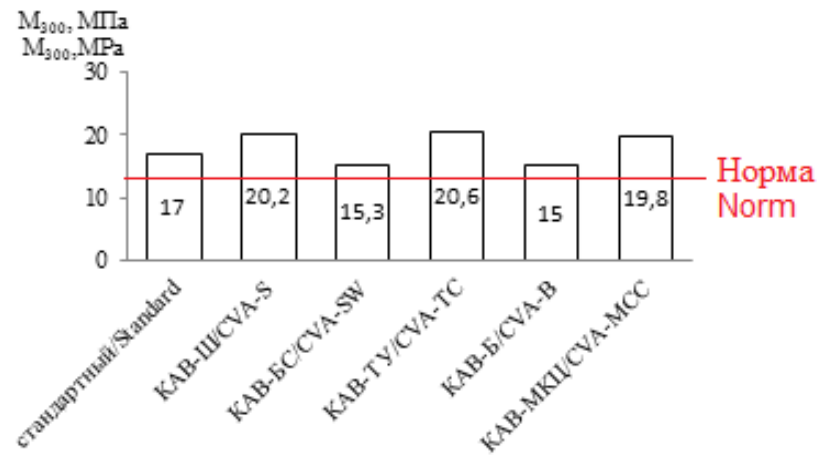

(a)

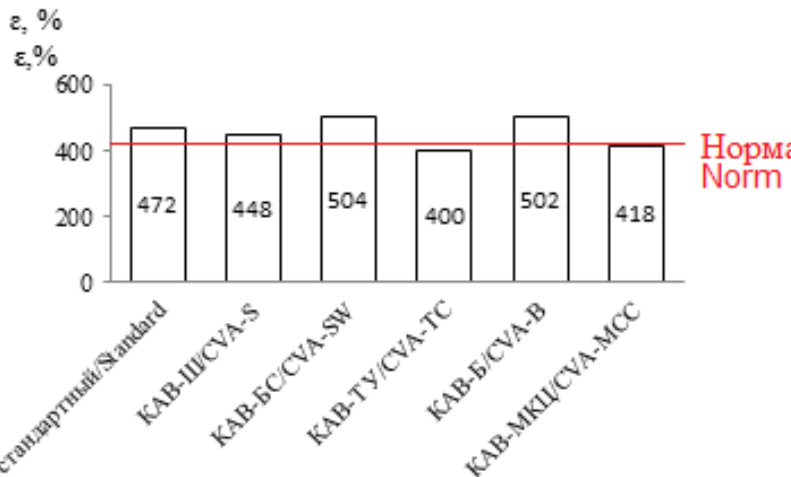

(c)

Таким образом, лучший комплекс упругопрочностных показателей имели вулканизаты с композиционными активаторами вулканизации, содержащими в качестве наполнителей шунгит и техуглерод.

По плотности поперечного сшивания эти образцы имели близкие значения, на что указывают структурные характеристики вулканизатов (таблица 3): равновесная степень набухания Qрсн, молекулярная масса между узлами вулканизационной сетки Мс и эффективная концентрация поперечных связей Nэф. В то же время все изучаемые активаторы вулканизации оказывают влияние на изменение модуля при растяжении (М300). Это может быть связано с проявлением активирующего действия применяемых тонкодисперсных порошков, а именно: вследствие высоких адсорбционных свойств применяемые наполнители могут адсорбировать на своей поверхности компоненты вулканизующей группы
По показателю условной прочности при растяжении (рисунок $1, b$ ) все образцы соответствовали нормам стандарта. Наблюдали увеличение прочности при растяжении $\mathrm{f}_{\mathrm{p}}$ до $10 \%$ при использовании КАВ с шунгитом и техуглеродом. Высокие значения относительного ( $(\varepsilon)$ и остаточного удлинений в комплексе с условным напряжением при удлинении на $300 \%$ образцов с активаторами на основе БС-120 и бентонита, очевидно, связаны с недовулканизацией этих резин.

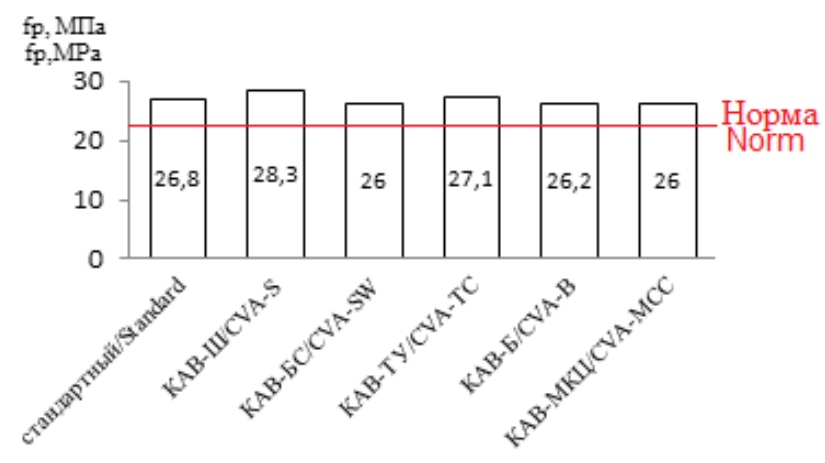

(b)

Рисунок 1. Зависимости физико-механических показателей стандартных резиновых смесей от типа применяемого наполнителя: $(a)-$ модуля при растяжении на 300\%; (b) - условная прочность при растяжении; $(c)$ - относительное удлинение

Figure 1. Dependence of physical and mechanical parameters of standard rubber compounds on the type of filler used: $(a)$ - modulus of tension at $300 \% ;(b)-$ conditional tensile strength; $(c)$ - elongation

и участвовать в реакциях образования действительных агентов вулканизации, далее в формировании пространственной сетки вулканизата [12].

Таблица 3 .

Структурные характеристики вулканизатов с различными активаторами вулканизации

Table 3 .

Structural characteristics of vulcanizates with different curing activators

\begin{tabular}{|c|c|c|c|}
\hline $\begin{array}{l}\text { Образец } \\
\text { Sample }\end{array}$ & $\begin{array}{l}\text { QPCH } \\
\mathrm{Q}_{\mathrm{RSN}} \\
\end{array}$ & $\begin{array}{c}\mathrm{M}_{\mathrm{C}}, \text { моль }^{-1} \\
\mathrm{M}_{\mathrm{C}, \mathrm{mol}^{-1}}\end{array}$ & $\begin{array}{l}\mathrm{N}_{\ni \Phi} \cdot 10^{-20} \\
\mathrm{~N}_{\ni \Phi} \cdot 10^{-20} \\
\end{array}$ \\
\hline $\begin{array}{l}\text { Стандартный } \\
\text { Standard }\end{array}$ & 3,64 & 414 & 6,56 \\
\hline КАB-Ш |CVA-S & 3,59 & 411 & 6,59 \\
\hline KAB - БC | CVA-SW & 2,93 & 369 & 7,35 \\
\hline \begin{tabular}{l|l} 
KAB-TУ & CVA-TC
\end{tabular} & 4,20 & 447 & 6,06 \\
\hline KAB-Б |CVA-B & 3,02 & 374 & 7,24 \\
\hline КАВ-МКЦ|CVA-MCC & 4,49 & 452 & 6,53 \\
\hline
\end{tabular}




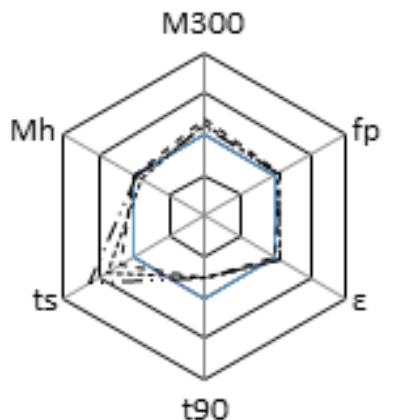

Рисунок 2. Сравнительный анализ основных свойств резиновых смесей и резин на основе композиционных активаторов вулканизации с различными наполнителями: - стандартный; - - - шунгит; - - - техуглерод; $-\times-\times-$ микроцеллюлоза

Figure 2. Comparative analysis of the basic properties of rubber mixes and rubbers on the basis of the compositional activators of vulcanization: - - - standard; - - - shungite; - - carbon black; $-\times-\times-$ microcellulose

Обобщённый анализ свойств резиновых смесей и вулканизатов с опытными активаторами вулканизации (рисунок 2) показал, что по активирующей способности и влиянию на технические свойства резин наилучшее влияние оказывают шунгит, техуглерод и МКЦ как наполнители опытных продуктов.

\section{Заключение}

Установлено, что использование тонкодисперсных наполнителей - шунгита, гранулированного технического углерода, кристаллической микроцеллюлозы при изготовлении композиционных активаторов вулканизации обеспечивает получение продукта в виде непылящего порошка. При этом полученные вулканизаты удовлетворяют нормам контроля, в некоторых случаях превосходят стандартные резины, содержащие активаторы вулканизации оксид цинка и стеариновую кислоту.

Установлена возможность уменьшения дозировки оксида цинка в резиновых смесях за счет использования КАВ, содержание оксида цинка в котором снижено в 5 раз. При этом обеспечивается сохранение требуемого уровня вулканизационных характеристик и физикомеханических показателей резин.

\section{Литература}

1 Большой справочник резинщика. Часть 1: Каучуки и ингредиенты; под ред. С.В. Резниченко, Ю.Л. Морозова. М.: ООО «Издательский центр «Техинформ» МАИ», 2012. 744 с.

2 Большой справочник резинщика. Часть 2: Резины и резинотехнические изделия; под ред. С.В. Резниченко, Ю.Л. Морозова. М.: ООО «Издательский центр «Техинформ» МАИ», 2012. 648 с.

3 Каблов В.Ф. Современные тенденции эволюции рецептов резин // Каучук и резина. 2018. № 5. С. 14-16.

4 Mostoni S., Milana P., Credico B. et al. Zinc-based curing activators: new trends for reducing zinc content in rubber vulcanization process // Catalysts. 2019. V. 9. № 8. P. 664.

5 Maciejewska M., Sowińska A., Kucharska J. Organic zinc salts as pro-ecological activators for sulfur vulcanization of styrene-butadiene rubber // Polymers. 2019. V. 11. № 10. P. 1723.

6 Alam M. N., Potiyaraj P. Synthesis of nano zinc hydroxide via sol-gel method on silica surface and its potential application in the reduction of cure activator level in the vulcanization of natural rubber // Journal of Sol-Gel Science and Technology. 2017. V. 81. № 3. P. 903-911.

7 Карманова О.В., Попова Л.В., Пойменова О.В. Создание активирующих систем для эффективной вулканизации эластомеров // Вестник ВГУИТ. 2014. № 3. С.126-129.

8 Gujel A.A. et al. Evaluation of vulcanization nanoactivators with low zinc content: characterization of zinc oxides, cure, physico-mechanical properties, $\mathrm{Zn} 2+$ release in water and cytotoxic effect of EPDM compositions // Polymer Engineering \& Science. 2018. V. 58. № 10. P. 1800-1809.

9 Sathi S.G. et al. Enhancing the efficiency of zinc oxide vulcanization in brominated poly (isobutylene-co-isoprene) rubber using structurally different Bismaleimides // Journal of Polymer Research. 2018. V. 25. № 5. P. 108.

10 Каюшников С.Н., Прокопчук Н.Р., Шашок Ж.С., Вишневский К.В. Свойства модельных резиновых смесей с различными активаторами вулканизации // Труды БГТУ. 2014. № 4 (168). С. 35-39.

11 Pogodaev A.K., Tikhomirov S.G., Karmanova O.V. et al. Modeling elastomer properties in presence of a composite vulcanization activator // Journal of Chemical Technology and Metallurgy. 2018. V. 53. № 5.

12 Глебова Ю.А., Шершнев В. А., Резниченко С.В. и др. Активирующее действие шунгита совместно с органическими солями цинка в резинах на основе ЭПДК // Каучук и резина. 2014. № 2. С. 34-36.

\section{References}

1 Great Rubber Handler Guide. Part 1: Rubbers and ingredients; under the editorship of S.V. Reznichenko, Yu.L. Morozova. Moscow, Publishing Center Tekhinform MAI LLC, 2012. 744 p. (in Russian).

2 Great Rubber Handler Guide. Part 2: Rubber and rubber products; under the editorship of S.V. Reznichenko, Yu.L. Morozova. Moscow, Publishing Center Tekhinform MAI LLC, 2012. 648 p. (in Russian).

3 Kablov V.F. Modern trends in the evolution of rubber recipes. Rubber and rubber. 2018. no. 5. pp. 14-16. (in Russian).

4 Mostoni S., Milana P., Credico B. et al. Zinc-based curing activators: new trends for reducing zinc content in rubber vulcanization process. Catalysts. 2019. vol. 9. no. 8. pp. 664.

5 Maciejewska M., Sowińska A., Kucharska J. Organic zinc salts as pro-ecological activators for sulfur vulcanization of styrene-butadiene rubber. Polymers. 2019. vol. 11. no. 10. pp. 1723. 
6 Alam M.N., Potiyaraj P. Synthesis of nano zinc hydroxide via sol-gel method on silica surface and its potential application in the reduction of cure activator level in the vulcanization of natural rubber. Journal of Sol-Gel Science and Technology. 2017. vol. 81. no. 3. pp. 903-911.

7 Karmanova O.V., Popova L.V., Poimenova O.V. Creation of activating systems for the effective vulcanization of elastomers. Proceedings of VSUET. 2014. no. 3. pp. 126-129. (in Russian).

8 Gujel A.A. et al. Evaluation of vulcanization nanoactivators with low zinc content: characterization of zinc oxides, cure, physico-mechanical properties, $\mathrm{Zn}^{2+}$ release in water and cytotoxic effect of EPDM compositions. Polymer Engineering \& Science. 2018. vol. 58. no. 10. pp. 1800-1809.

9 Sathi S.G. et al. Enhancing the efficiency of zinc oxide vulcanization in brominated poly (isobutylene-co-isoprene) rubber using structurally different Bismaleimides. Journal of Polymer Research. 2018. vol. 25. no. 5. pp. 108.

10 Kaushnikov S.N., Prokopchuk N.R., Shashok Zh.S., Vishnevsky K.V. Properties of model rubber compounds with various vulcanization activators. Transactions of BSTU. 2014. no. 4 (168). pp. 35-39. (in Russian).

11 Pogodaev A.K., Tikhomirov S.G., Karmanova O.V. et al. Modeling elastomer properties in presence of a composite vulcanization activator. Journal of Chemical Technology and Metallurgy. 2018. vol. 53. no. 5.

12 Glebova Yu.A., Shershnev V.A., Reznichenko S.V. et al. The activating effect of shungite in conjunction with organic zinc salts in rubbers based on EPDK. Rubber and rubber. 2014. no. 2. pp. 34-36. (in Russian).

\section{Сведения об авторах}

Ольга В. Карманова д.т.н., кафедра технологии органических соединений, переработки полимеров и техносферной безопасности, Воронежский государственный университет инженерных технологий, пр-т Революции, 19, г. Воронеж, 394036, Россия, karolga@ mail.ru (Dhttps://orcid.org/0000-0003-2226-6582

Анастасия Ю. Фатнева аспирант, кафедра полимеров и техносферной безопасности, Воронежский государственный университет инженерных технологий, пр-т Революции, 19, г. Воронеж, 394036, Россия, doroxinanastja@mail.ru (Dhttps://orcid.org/0000-0003-0109-7222

Сергей Г. Тихомиров д.т.н., профессор, кафедра информационных и управляющих систем, Воронежский государственный университет инженерных технологий, пр-т Революции, 19, г. Воронеж, 394036, Россия, tikhomirov_57@mail.ru

(Dhttps://orcid.org/0000-0002-8192-0049

Любовь В. Попова к.т.н., доцент, кафедра промышленной экологии, оборудования химических и нефтехимических производств, Воронежский государственный университет инженерных технологий, пр-т Революции, 19, г. Воронеж, 394036, Россия, luba030883@yandex.ru

(Dhttps://orcid.org/0000-0002-9648-7620

\section{Вклад авторов}

Ольга В. Карманова предложила методику проведения эксперимента, корректировала рукопись до подачи в редакцию Анастасия Ю. Фатнева обзор литературных источников по исследуемой проблеме, провела эксперимент, выполнила расчёты, написала рукопись и несет ответственность за плагиат Сергей $\Gamma$. Тихомиров организовал производственные испытания

Любовь В. Попова консультация в ходе исследования

Конфликт интересов

Авторы заявляют об отсутствии конфликта интересов.

\section{Information about authors}

Olga V. Karmanova Dr. Sci. (Engin.), technology of organic compounds, processings of polymers and technosphere safety department, Voronezh State University of Engineering Technologies, Revolution Av., 19 Voronezh, 394036, Russia, karolga@mail.ru Dhttps://orcid.org/0000-0003-2226-6582

Anastasia Yu. Fatneva graduate student, technology of organic compounds, processing of polymers and technosphere safety department, Voronezh State University of Engineering Technologies, Revolution Av., 19 Voronezh, 394036, Russia, doroxinanastja@mail.ru

(iDhttps://orcid.org/0000-0003-0109-7222

Sergei G. Tikhomirov Dr. Sci. (Engin.), information and control systems department, Voronezh State University of Engineering Technologies, Revolution Av., 19 Voronezh, 394036, Russia, tikhomirov_57@mail.ru

(Dhttps://orcid.org/0000-0002-8192-0049

Lubov V. Popova Cand. Sci. (Engin.), professor, industrial ecology, equipment of chemical and petrochemical productions department, Voronezh State University of Engineering Technologies, Revolution Av., 19 Voronezh, 394036, Russia, luba030883@yandex.ru

Dhttps://orcid.org/0000-0002-9648-7620

\section{Contribution}

Olga V. Karmanova proposed the method of the experiment, corrected the manuscript before submitting to the editor

Anastasia Yu. Fatneva review of literature on the problem under study, conducted an experiment, performed calculations, wrote a manuscript and is responsible for plagiarism

Sergei G. Tikhomirov organized production trials

Lubov V. Popova consultation during the study

Conflict of interest

The authors declare no conflict of interest.

\begin{tabular}{ccc}
\hline Поступила 25/10/2019 & После редакции 05/11/2019 & Принята в печать 14/11/2019 \\
\hline Received 25/10/2019 & & Accepted 14/11/2019 \\
\hline
\end{tabular}

